Collection/Special issue: COST action FP1407

"Understanding wood modification through an integrated scientific and environmental impact approach"

Guest Editors: Giacomo Goli, Andreja Kutnar, Dennis Jones, Dick Sandberg

\title{
Kinetic analysis of poplar wood properties by thermal modification in conventional oven
}

\author{
Bertrand Marcon ${ }^{(1-2-3)}$, \\ Giacomo Goli ${ }^{(2)}$, \\ Miyuki Matsuo-Ueda ${ }^{(4)}$, \\ Louis Denaud ${ }^{(1)}$ \\ Kenji Umemura ${ }^{(3)}$, \\ Joseph Gril ${ }^{(5)}$, \\ Shuichi Kawai ${ }^{(6)}$
}

\begin{abstract}
The kinetics of several poplar (Populus alba L.) wood properties during thermal modification conducted in conventional oven with air recirculation were analysed and modelled in this paper. A wide range of properties was assessed, such as: equilibrium moisture content, sorption diagram, shrinkage coefficients, specific shrinkage coefficients, mass loss, modulus of elasticity, strength and colour. The tests were executed at different temperatures ranging from $90{ }^{\circ} \mathrm{C}$ to $180{ }^{\circ} \mathrm{C}$ and with different durations. The time-temperature equivalency was checked and property modifications over time analysed through master curves in order to obtain a general model connecting together properties, treatment temperature and duration. Different activation energies arising from each property evolution with treatment temperature and duration are provided showing that every modification could occur with different kinetics.
\end{abstract}

Keywords: Poplar Wood Modification, Heat Treatment, Time-temperature Equivalency, Energy of Activation, Kinetic Analysis, Mechanical Properties, $\mathrm{Hy}$ groscopicity, Wood Colour quence, a large number of methods were developed over the years, and a considerable research is still on-going to get a better understanding of the reactions involved. As a consequence, many treatment technologies are actually available on the market (Rapp 2001, Johansson 2005), and the general principles of wood thermal degradation are well documented in textbooks such as Navi \& Sandberg (2012) and Hill (2006). The whole field of thermo-hydro processing of wood was subjected to large review papers such as Esteves \& Pereira (2009) and Sandberg et al. (2013); those studies make partially the point on the different effects of thermal modification on properties.

A promising field of application for ther-

(1) LaBoMaP, Arts et Métiers ParisTech, Cluny (France); (2) GESAAF, University of Florence, Florence (Italy); (3) Laboratory of Sustainable Materials, University of Kyoto, Kyoto (Japan); (4) Laboratory of Bio-Material Physics, University of Nagoya, Nagoya (Japan); (5) CNRS, University of Clermont Auvergne, Institut Pascal, Clermont-Ferrand (France); (6) Graduate School of Advanced Integrated Studies in Human Survivability, University of Kyoto, Kyoto (Japan)

@ Bertrand Marcon (bertrand.marcon@ensam.eu)

Received: Mar 09, 2017 - Accepted: Nov 23, 2017

Citation: Marcon B, Goli G, Matsuo-Ueda M, Denaud L, Umemura K, Gril J, Kawai S (2018). Kinetic analysis of poplar wood properties by thermal modification in conventional oven. iForest 11: 131-139. - doi: 10.3832/ifor2422-010 [online 2018-02-07]

Communicated by: Giacomo Goli

mal modification is to consider the artificial aging of wood for special applications in cultural heritage. Many questions about the behaviour of wooden material during aging are still unanswered; wood researchers are more and more investigating cultural heritage problems (Marcon 2009, Dureisseix \& Marcon 2011). Indeed, because it is often impossible to perform mechanical tests on wood from the cultural heritage, it is practically very difficult to describe the effect of aging on wood. Moreover, the previous conditions of any given specimen of historical wood is usually poorly documented and can only be guessed. Actually, it is well known that aged wood and freshly cut wood have significant hygro-mechanical differences (Esteves \& Pereira 2009, Enayati \& Taheri 2012). The only alternative to destructive tests on cultural heritage artefacts, to get information about aged wood, is to make artificial aging via thermal modification (Obataya et al. 2006). Previous works conducted in Japan (RISH Institute and Tsukuba University) have shown similarities in colour properties between naturally aged wood and thermally modified wood (Matsuo et al. 2011, 2016). These studies were mainly carried out on Japanese softwoods traditionally used in construction. Other studies consider thermal modification as very close to natural aging (Froidevaux et al. 2012, Ganne-Chédeville et al. 2012). As a first coarse approximation thermal modification in conventional oven seems to produce similar results than natural aging; 
Tab. 1 - Main properties of the unmodified material at oven dry conditions (o\% MC).

\begin{tabular}{|c|c|c|c|c|}
\hline \multirow{2}{*}{ Properties } & \multirow{2}{*}{ Variable } & \multicolumn{3}{|c|}{ Series } \\
\hline & & L-samples & R-samples & RT-samples \\
\hline \multirow{13}{*}{ 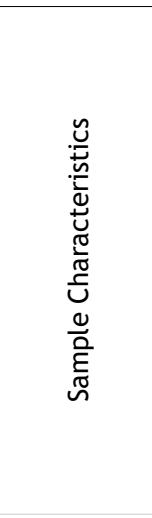 } & Dimensions $(\mathrm{mm}, \mathrm{L} \times \mathrm{R} \times \mathrm{T})$ & $120 \times 20 \times 2$ & $2 \times 60 \times 10$ & $3 \times 40 \times 40$ \\
\hline & No. of samples & 288 & 314 & 110 \\
\hline & $\rho_{\circ}\left(\mathrm{g} \mathrm{cm}^{-3}\right)$ & $0.31 \pm 0.03$ & $0.31 \pm 0.02$ & $0.29 \pm 0.01$ \\
\hline & $M O E_{\text {od }}(\mathrm{GPa})$ & $8.57 \pm 0.72$ & $0.66 \pm 0.06$ & - \\
\hline & $s M O E_{\text {od }}\left(\mathrm{GPa} \mathrm{kg} \mathrm{m}{ }^{-3}\right)$ & $27.30 \pm 1.00$ & $2.12 \pm 0.11$ & - \\
\hline & $M O R_{\text {od }}(\mathrm{MPa})$ & $93.90 \pm 11.40$ & $10.78 \pm 0.93$ & - \\
\hline & $s M O R_{\text {od }}\left(M P a \mathrm{~kg} \mathrm{~m}^{-3}\right)$ & $0.30 \pm 0.02$ & $35.00 \pm 2.00$ & - \\
\hline & $L^{*}$ od & $83.00 \pm 1.50$ & - & - \\
\hline & $a_{\text {od }}^{*}$ & $5.00 \pm 0.90$ & - & - \\
\hline & $b_{\text {od }}^{*}$ & $19.20 \pm 1.70$ & - & - \\
\hline & $\beta_{0-85 \% \mathrm{RH} \_}^{\mathrm{S}} R$ & - & - & $0.13 \pm 0.03$ \\
\hline & $\beta_{0-85 \% \text { RH_}}^{\mathrm{S}} T$ & - & - & $0.20 \pm 0.02$ \\
\hline & $\beta_{0-85 \% \mathrm{RH} \_L}^{\mathrm{S}}$ & - & - & $0.03 \pm 0.01$ \\
\hline \multirow{7}{*}{ 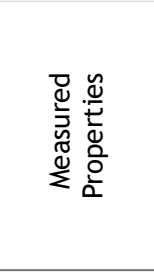 } & Colour & Yes & No & No \\
\hline & Mechanical tests & Yes & Yes & No \\
\hline & Dimensions & Yes & Yes & Yes \\
\hline & Mass & Yes & Yes & Yes \\
\hline & Swelling coefficients & No & No & Yes \\
\hline & Moisture content & No & No & Yes \\
\hline & Sorption curve & No & No & Yes \\
\hline
\end{tabular}

however, the physical properties of aged wood depends also on its hygroscopic history (Endo et al. 2016). Strictly speaking, oven-heated wood is partially different from naturally-aged wood because natural ageing proceeds at moderate relative humidity and not at a dry state. In addition, chemical reactions induced by heating above $150{ }^{\circ} \mathrm{C}$ seems to be qualitatively different from those below $150{ }^{\circ} \mathrm{C}$, according to Ganne-Chédeville et al. (2012).

The data summarized in this study will be useful for modelling and simulating poplar wood modification process by heat treatment. Until now, several scientific works

Tab. 2 - Schedule of thermal modification performed in ventilated oven. (a): about 7.5 months; (b): about 5.5 months; (c): about 1 month; (d): one week.

\begin{tabular}{|c|c|c|c|c|}
\hline \multirow{2}{*}{-} & \multicolumn{4}{|c|}{ Temperatures $\left({ }^{\circ} \mathrm{C}\right)$} \\
\hline & 90 & 120 & 150 & 180 \\
\hline \multirow{18}{*}{ 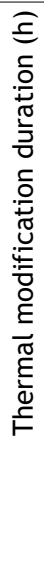 } & 311 & 43 & 4 & 0.5 \\
\hline & 643 & 66 & 9 & 1 \\
\hline & 1056 & 139 & 20 & 2 \\
\hline & 1539 & 209 & 26 & 3 \\
\hline & 2569 & 338 & 44 & 5 \\
\hline & 3602 & - & 60 & 7 \\
\hline & $5542^{(a)}$ & 643 & 82 & - \\
\hline & - & 811 & 100 & 13 \\
\hline & - & 980 & 130 & - \\
\hline & - & 1171 & 166 & 23 \\
\hline & - & 1539 & 214 & 31 \\
\hline & - & 2323 & 334 & 36 \\
\hline & - & 3072 & 411 & 51 \\
\hline & - & $3842^{\text {(b) }}$ & 504 & 62 \\
\hline & - & - & $600^{(c)}$ & 78 \\
\hline & - & - & - & 103 \\
\hline & - & - & - & 127 \\
\hline & - & - & - & $168^{(\mathrm{d})}$ \\
\hline
\end{tabular}

used general energies of activation to model the kinetic of mass-loss during drying process (Chaouch et al. 2013, Pétrissans et al. 2014, Candelier et al. 2015). The mass loss is widely considered as a good indicator of mechanical performances (Pétrissans et al. 2014) and durability against inand fungal attack (Kamdem et al. 2002). Nevertheless, considering all properties changes at the same moment with the same rate is not satisfying; the present work will enhance the understanding of wood properties evolution during heat treatment using objective descriptors already exposed in a previous work (Goli et al. 2014) on mass loss, but here extended ties.

\section{Material and methods}

\section{Specimens preparation and} conditioning

The wood used for this study was Italian Populus alba L. with a density $(\rho)$ of about $0.34 \pm 0.02 \mathrm{~g} \mathrm{~cm}^{-3}$ at standard environmental conditions, $20^{\circ} \mathrm{C}$ of temperature $(\mathrm{T})$ and $65 \%$ of relative humidity $(\mathrm{RH})$. The annual ring width was $10 \pm 2 \mathrm{~mm}$ and the estimated age of the tree 30 years. In order to investigate the moisture relations, physical and mechanical properties of unmodified and thermally modified wood material, different types of specimens were cut from heartwood following the anatomical orientations: longitudinal ( $L$ ), radial $(R)$, tangential $(T)$. A series named L-samples measuring $120(\mathrm{~L})$ by $20(\mathrm{R})$ by $2(\mathrm{~T}) \mathrm{mm}^{3}$ were used to assess the colour variation in LR plane and the bending stiffness and strength in $\mathrm{L}$ direction. A series named $\mathrm{R}$ sects (Candelier et al. 2016, Gérardin 2016) to other physical and mechanical proper- samples measuring $2(\mathrm{~L})$ by $60(\mathrm{R})$ by $10(\mathrm{~T})$ $\mathrm{mm}^{3}$ were used to assess the bending stiffness in $R$ direction. Finally a series named RT-samples measuring $3(\mathrm{~L})$ by $40(\mathrm{R})$ by 40 ( $T$ ) $\mathrm{mm}^{3}$ were used to assess the $R$ and $T$ shrinkage. A detailed description of the specimens is given in Tab. 1 .

Out of the total amount of specimens prepared (480 L-samples, 600 R-samples, and 175 RT-samples), a selection was done by removing from the experiment the specimens with a specific modulus of elasticity ( $S M O E)$ above or below the value of $s M O E \pm \sigma$, ending to reduce the number of samples to $288 \mathrm{~L}$-samples, $314 \mathrm{R}$-samples, and 110 RT-samples.

\section{Thermal modification}

The specimens were kept for 3 weeks at environmental standard conditions $(20 \pm 2$ ${ }^{\circ} \mathrm{C}$ and $63 \pm 2 \% \mathrm{RH}$ with $\mathrm{NaBr}$ salt powder in excess in distilled water). To determine their dry mass before the thermal modification they were dried at $60^{\circ} \mathrm{C}$ in a vacuum oven with $\mathrm{P}_{2} \mathrm{O}_{5}$ salts for 24 to 48 hours depending on their dimensions. The dried specimens were then thermally modified in a ventilated oven at four different temperatures: $90,120,150$, and $180{ }^{\circ} \mathrm{C}$. The $90{ }^{\circ} \mathrm{C}$ thermal modification treatment is a very mild treatment that can be very helpful to understand if other reactions take part at higher temperatures or if the model can be extended at lower temperatures. Goli et al. (2014) studied the effect of air exchange rate $(A E R)$ on the modifications kinetic (mass loss); the heat treatments presented in this study had been performed at the same air exchange rate, $A E R=220 \mathrm{AE}$ day $^{-1}$. The treatments schedule is presented in Tab. 2 and it was developed on the base of a time/temperature equivalence assumption, where a $10^{\circ} \mathrm{C}$ increase in temperature results in dividing the treatment time by two as largely reported in literature (Stamm 1956, Dlouhá et al. 2009).

At $90{ }^{\circ} \mathrm{C}$ a treatment period up to 7.5 months was scheduled while at $180{ }^{\circ} \mathrm{C}$ only 168 hours ( 1 week) were necessary, showing the large sensitivity of the process to temperature. It is important to notice that most of the properties given in the following sections are measured at oven dry condition. Only equilibrium moisture content (EMC) and shrinkage coefficient involved tests at different moisture contents.

\section{Colour measurement}

At each treatment step the colour was measured on the oven-dry samples using a Konica Minolta CM-260od device and expressed with $\mathrm{CIE}-L^{*} a^{*} b^{*}$ system. The parameters $L^{*}, a^{*}, b^{*}$ and $\Delta E_{a b}{ }^{*}$ under a D65 light source and an observation angle of $10^{\circ}$ are reported (see Fig. 1c). The measuring area was a circle of $8 \mathrm{~mm}$ diameter. The colour measurement was done only for Lsamples on the tangential face. On each specimen three measurements were done in three different locations and averaged. The variation of $\Delta L^{*}, \Delta a^{*}, \Delta b^{*}$, and the to- 

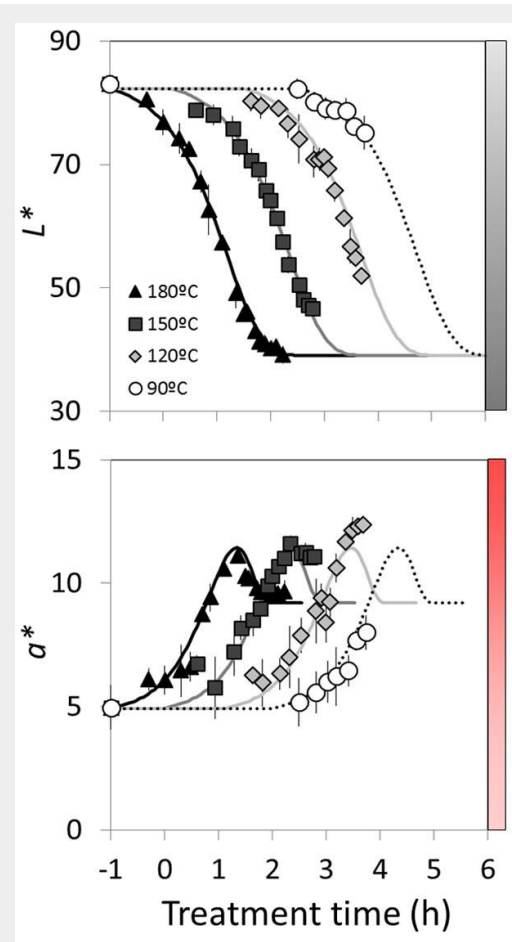

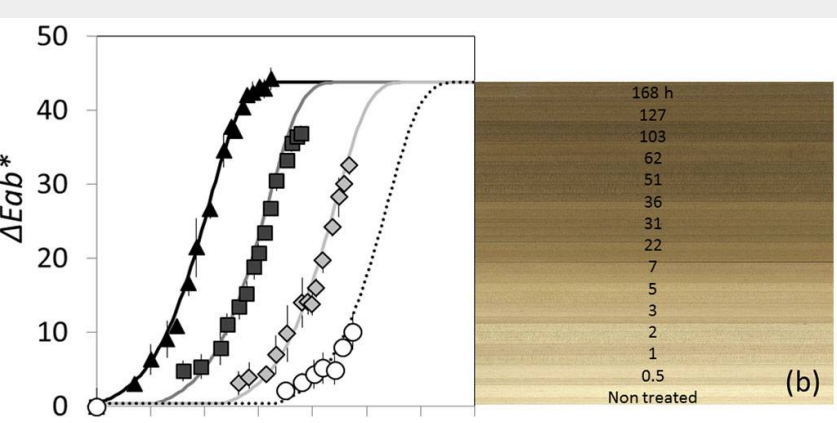

30

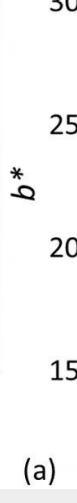

(a)

\section{0}

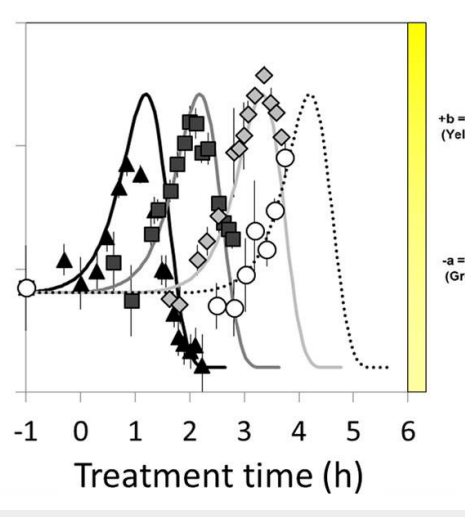

Fig. 1 - (a) Colour evolutions due to the heat treatments performed measured under a D65 light source and an observe angle of $10^{\circ}$. (b) Colour evolution on samples treated at $180^{\circ} \mathrm{C}$ depending on the time of treatment (in hours). (c) 3D representation of the CIE $L^{*} a * b^{*}$ colour space. Markers are the experimental colour measurements and the lines are the application of the model proposed. tal colour variation $\Delta E_{a b} *$ were calculated using the following formulas (Bekhta \& Niemz 2003, Matsuo et al. 2016 - eqn. 1, eqn. 2):

$$
\begin{aligned}
& \Delta L^{*}=L^{*}-L_{0}^{*} \\
& \Delta a^{*}=a^{*}-a_{0}^{*} \\
& \Delta b^{*}=b^{*}-b_{0}^{*} \\
& \Delta E_{a b}^{*}=\sqrt{\Delta L^{* 2}+\Delta a^{* 2}+\Delta b^{* 2}}
\end{aligned}
$$

\section{Moisture relations assessment}

mass losses determined as a relative mass loss from the initial value. The variation of density was also computed from mass and dimensions measurements. two main purposes: to determine sorption isotherms of the modified material as well as the shrinkage coefficients. The sorption

where $L^{*}$ is the lightness, $a^{*}$ and $b^{*}$ are the colour coordinates and "o" (in subscript) indicates the reference values obtained as the average of the 288 untreated specimens before heat treatment and in oven dry state.

\section{Physical properties assessment}

Samples dimensions in oven dry state were measured before and after the thermal modification by a self-designed apparatus implying Mitutoyo digital gauges with $0.001 \mathrm{~mm}$ of accuracy and dedicated spindle lifting cables to enhance test repeatability. The mass was determined by an analytical balance with $0.001 \mathrm{~g}$ accuracy. The dimensional variations during the treatment in the different anatomic directions was measured at dry state, while the dry isotherms were determined for RT-samples using boxes at constant $\left(20^{\circ} \mathrm{C}\right.$ inside a climatic chamber) and four RH levels: $35 \%$, $52 \%, 63 \%$ and $85 \%$ obtained by salt dissolution technique as from Young (1967 - see Tab. 3 for details on the salts used).

The dry mass used as reference was obtained after a stage at $60{ }^{\circ} \mathrm{C}$ in a vacuum oven with $\mathrm{P}_{2} \mathrm{O}_{5}$ salts for 24 to 48 hours depending on the dimensions of the specimens and measured at $20^{\circ} \mathrm{C}$. At the different conditions, once the equilibrium moisture content was reached (this was checked by verifying the stability of the mass), the equilibrium moisture content $(E M C)$ was determined according to eqn. 3:

$$
E M C_{(\% R H)}=\frac{m_{(\% R H)}-m_{o d}}{m_{o d}} \cdot 100
$$

with $m_{\text {\%RH })}$ and $m_{\text {od }}$ are the weight of the samples at the given $\mathrm{RH}$ and oven dry state, respectively. The swelling coefficient $(\beta)$ and the specific shrinkage coefficient $\left(\beta^{5}\right)$ were determined considering the dimension at the various $E M C$ levels at $20^{\circ} \mathrm{C}$ and the dimension at dry state and computed according to eqn. 4 and eqn. 5:

$$
\begin{aligned}
& \beta_{R \vee T \vee L}=\frac{\operatorname{dim}_{R \vee T \vee L}^{o / R H}-\operatorname{dim}_{R \vee T \vee L}^{o d}}{\operatorname{dim}_{R \vee T \vee L}^{o d}} \cdot 100 \\
& \beta_{R \vee T \vee L}^{S}=\frac{\beta_{R \vee T \vee L}}{E M C_{(R H)}}
\end{aligned}
$$

where $\operatorname{dim}_{R}{ }^{\text {\%RH }}$ is the measured dimensions of the RT-specimens in the given anatomical direction (here $\mathrm{R}$ stands for radial) at the equilibrium state with the different relative humidity conditions at $20{ }^{\circ} \mathrm{C}, \operatorname{dim}_{R}{ }^{\text {od }}$ are the same specimens measured at oven dry state, and $E M C_{(\mathrm{RH})}$ is the moisture content determined at the different equilibrium conditions. The isotherms were modelled using the Guggenheim, Anderson and Boer-Dent (GAB) expression. This model is particularly appropriate for food materials and widely used for multi-layer materials such as wood (Bratasz et al. 2011). GAB system general equation is reported in eqn. 6 :

$E M C_{(R H)}=w_{m} \frac{C \cdot K \cdot R H}{(1-K \cdot R H)(1-K H+C \cdot K \cdot R H)}$

Tab. 3 - Salts and environmental conditions used for the construction of the sorption isotherms and the computation of shrinkage coefficients.

\begin{tabular}{lccc}
\hline Techniques & Temperature $\left({ }^{\circ} \mathrm{C}\right)$ & Relative humidity & Duration (days) \\
\hline Vacuum oven-drying $+\mathrm{P}_{2} \mathrm{O}_{5}$ & 60 & $\approx 0 \%$ & $>1$ \\
$\mathrm{MgCl}_{2}$ salt in excess & 20 & $35 \%$ & $>14$ \\
$\mathrm{Climatic} \mathrm{chamber} \mathrm{Memmert}^{\circ}$ & 20 & $52 \%$ & $>7$ \\
$\mathrm{NaBr}$ salt in excess & 20 & $63 \%$ & $>14$ \\
$\mathrm{KCl}$ salt in excess & 20 & $85 \%$ & $>14$ \\
\hline
\end{tabular}


with an Instron ${ }^{\odot}$ material testing machine at oven-dry state. The mass of the tested samples was measured before and after the bending test; the moisture content variation through the test was lower than $2 \%$. The tests were performed with a crosshead speed of $5 \mathrm{~mm} \mathrm{~min}{ }^{-1}$. The following properties were determined: the Young's modulus (MOE) and the strength (MOR) in $\mathrm{L}$ and $\mathrm{R}$ directions, the breaking strain $\left(\varepsilon_{\mathrm{m}}\right)$ and the breaking energy $(\mathrm{W})$.

\section{Kinetic analysis}

It is widely accepted that the classical Arrhenius law suits very well for the timetemperature equivalence analysis (Struik 1978, Herrera et al. 1986, Gillen \& Clough 1989, Hutchinson 1995, Dlouhá et al. 2008, Goli et al. 2014). The Arrhenius law in classical format is reported in eqn. 7:

$$
k=A_{(T)} \cdot \exp \left(-\frac{E_{a}}{R T}\right)
$$

where $k$ is the rate constant (dimensionless) of the chemical reaction considered, $A_{T}$ is the pre-exponential factor (dimensionless) with temperature dependency, $E_{a}$ the apparent activation energy (in $\mathrm{kJ} \mathrm{mol}^{-1}$ ), $R=$ $8.314 \mathrm{~J} \mathrm{~mol}^{-1} \mathrm{~K}^{-1}$ is the universal gas constant and $T$ the absolute temperature (in ${ }^{\circ} \mathrm{K}$ ) of the reaction. Considering the pre-exponential factor as a constant usually gives quite good results. This assumption leads to a linear variation in the Arrhenius plots as used for example in Goli et al. (2014). To improve the accuracy of the method some modified Arrhenius law were proposed to express the temperature dependency, as in Brown (1982) and Herrera et al. (1986) who showed a bi-linear law instead of the widely used linear one and a constant pre-exponential factor, or in Dlouhá et al. (2009) who added a softening effect with temperature. A non-constant pre-exponential factor is then introduced by (Laidler 1996) as shown in eqn. 8:

$$
k=A \cdot T^{n} \cdot \exp \left(-\frac{E_{a}}{R T}\right)
$$

where the pre-exponential factor $A$ is here a constant and the temperature power $n$ is an empirical dimensionless constant typically lying in the range $-1<n<1$. The model is completed by the computation of the horizontal (log time) shift factor $\left(a_{\mathrm{T}}\right)$ to reach the correspondence between the curve obtained at the given temperature $T$ and the one at the reference temperature $T_{\text {ref }}$ as shown in eqn. 9:

$$
a_{T}=\frac{t_{T}}{t_{T_{r f}}}=\exp \left[\frac{E_{a}}{R} \cdot\left(\frac{1}{T}-\frac{1}{T_{r e f}}\right)\right]
$$

Some authors discussed the validity of Arrhenius law linearity to explain reaction rates and time-temperature effects (Brown 1982, Agrawal 1985, Hutchinson 1995, Struik 1997). However, in the case of samples free from external loads during the thermal modification and at quite low tem-
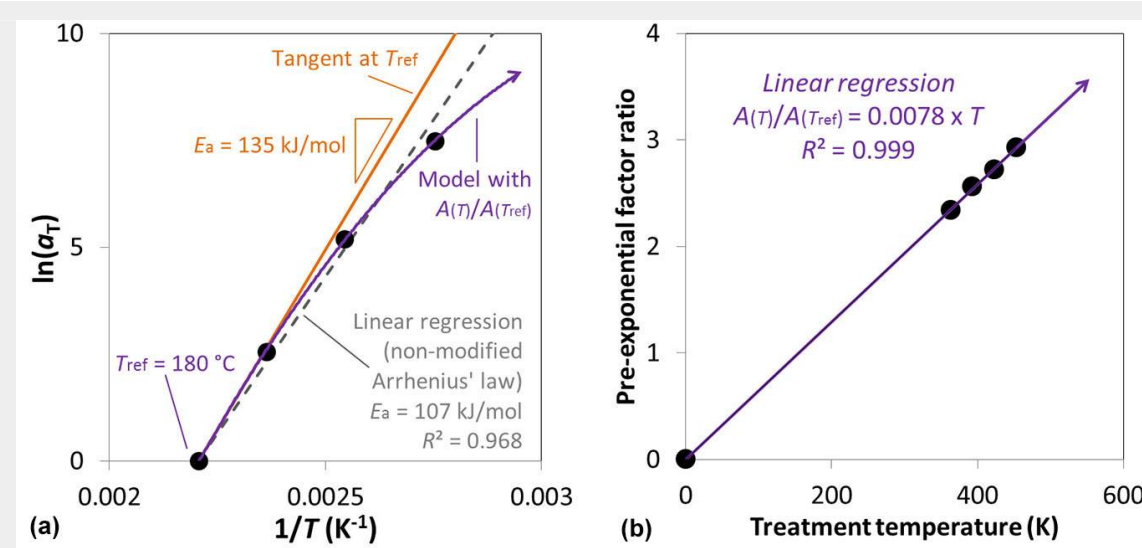

Fig. 2 - (a) Moisture content Arrhenius plot of the horizontal shift factor with different fitting strategies: a global linear regression (dashed grey line) highlights how the linear approach without pre-exponential factor $\left(A_{(T)} / A_{(T-r e f)}=1\right)$ can be limited and how the use of a non-linear (purple continuous line) pre-exponential factor $\left(A_{(T)} / A_{(T-r e f)} \neq 1\right)$ can be used to improve the fitting; $a_{\mathrm{T}}$ is the horizontal shift factor. (b) The perfect fit of the model using the pre-exponential factor as linearly dependent of the treatment temperature is displayed.

perature, there is no doubt on the relevance of the law application. Besides, others authors have applied the model to structural modification such as Repellin \& Guyonnet (2005).

\section{Results and discussion}

In this section, the Arrhenius law applicability is verified and the evolution of the physical and mechanical properties with treatment temperature and duration is reported; both experimental and modelled data are shown. The parameters used to perform the whole modelling are summarized in Tab. S1 (Supplementary material) on the theoretical basis of Goli et al. (2014) improved with the pre-exponential factor dependency to temperature as presented in the following subsection.

\section{Kinetic analysis}

An observation of the Arrhenius plots of the moisture content evolution is presented in Fig. 2a; only this plot is shown out of all the analyses performed for the sake of brevity. As for the Arrhenius plots present in the extensive works of Matsuo et al. (2011, 2016), a simple non-modified Arrhenius law could exhibit some weakness. To be more specific, the non-modified approach is very suitable when it comes to model evolutions in the range of temperatures considered to identify the model (as for the previously cited works) and its energy of activation. For instance, the model accuracy is $R^{2}=0.968$ for a non-modified Arrhenius approach (Fig. 2a). Nonetheless, several authors expressed limitations and advices to reconsider the application of the non-modified Arrhenius law in favour to a modified one (Ströfer-Hua 1990, Barbero \& Ford 2004, Calvini et al. 2008). Hence, to obtain a predictive model for temperature out of the temperature domain studied (used for the identification), it is absolutely necessary to improve the determination of the kinetic law. To such purpose, the present study introduces a new way to express the pre-exponential temperature dependency, since it seems logical to consider a constant energy of activation, constituting a material property of the wooden species for the considered property. Consequently, the energy of activation is determined as being the slope of the tangent at the chosen reference temperature (here $T_{\text {ref }}=180$ ${ }^{\circ} \mathrm{C}$ ) divided by the universal gas constant $(R)$. Hence, here is considered a pre-exponential factor function of the temperature considered, as define by the eqn. 10 .

$$
k=A_{(T)} \cdot \exp \left(-\frac{E_{a}}{R T}\right)
$$

where the pre-exponential factor has to be identified experimentally and probably depends of the wooden species, as suggested by previous works (Matsuo et al. 2011, 2016).

Fig. $2 \mathrm{~b}$ shows the identification obtained using the EMC data and provides the evolution of the pre-exponential factor as (eqn. 11):

$$
A_{(T)} / A_{\left(T_{r e f}\right)}=0.0078 \cdot T
$$

for $T_{\text {ref }}=180{ }^{\circ} \mathrm{C}$. This pre-exponential temperature dependency has been checked on the whole properties considered in this study and results as very accurate for all of them; those other plots are not presented. All the kinetic models proposed for all the properties, summarized in Tab. S1 (Supplementary material), are considering this preexponential dependency to temperature.

\section{Colour modification}

The effect of the thermal modification on the samples colour is shown in Fig. 1a. It has the effect to reduce considerably the lightness ( $\left.L^{*}\right)$ by $53 \%$ (from 89 to 39 ), resulting in an important darkening (Fig. 1b). 
This darkening leads to an increase in $E_{a b}{ }^{*}$, which is mainly driven by a decrease in $L^{*}$, since the variations of $a^{*}$ and $b^{*}$ are relatively less important. On the other hand, while $L^{*}$ presents a continuous reduction, the $a^{*}$ and $b^{*}$ chromatic parameters result in more complex behaviours, increasing at a first stage and decreasing in a second stage; this is the result of a first oxidation reaction followed afterward by a degradation of the constitutive hemicelluloses polymers. The hemicelluloses starts to decay at about $120^{\circ} \mathrm{C}$ (Tjeerdsma et al. 1998), through a deacetylation process that creates acetic acid acting as a catalyser for subsequent depolymerisation (Fengel \& Wegener 1989, Tjeerdsma et al. 1998) and a lignin reticulation (Stamm 1956, Tjeerdsma et al. 1998, Repellin \& Guyonnet 2005). Emsley \& Stevens (1994) indicates that the cellulose compound experiences a decomposition process to furfural, then proceeds by a series of rearrangement and elimination reactions as also reported by Shafizadeh \& Peter (1977). Both $a^{*}$ and $b^{*}$ evolution are the result of those different chemical reactions occurring at different treatment times; they remain in the $\mathrm{CIE}-L^{*} a^{*} b^{*}$ reddish and yellowish areas leading to the orange/brown colour.

For $a^{*}$ and $b^{*}$, a moderate increase of their maximum value can be observed. Several authors (Hutchinson 1995, Struik 1997, Dlouhá et al. 2009) observed such effect and applied a vertical shift factor (usually referred as $b_{T}$ ) in addition to the more classical horizontal shift factor (in log time axis); this effect is not taken into account in this model, since it has not been fully identified over a wide range of temperatures.

\section{Physical properties modification}

The relative reduction (\%) of the oven-dry dimensions consecutive to the thermal modification are reported in Fig. 3. This re- duction was measured separately for $L, R$ and $T$ directions. As it can be observed, the trends are very clear and the model follows the experimental results. The reduction is conspicuous for $\mathrm{T}$ and $\mathrm{R}$ directions, while it is negligible in the $L$ direction. The ratio between $T$ and $R$ reduction is about 2 , being the same as the $T$ over $R$ ratio of drying shrinkage coefficients for unmodified wood. These data confirm that hemicelluloses suffer a larger thermal degradation compared to the other wood constituents, considering their dominant contribution to the drying shrinkage in the transverse directions. On the other hand, the longitudinal bonds of wood are less affected since the shortening in this direction is negligible. The relative reduction in volume (\%) at dry state shows a trend very similar to $T$ and $\mathrm{R}$ directions with an excellent accuracy of the model. Oven-dry mass and oven-dry density show the same behaviour, highlighting how the main physical properties exhibit the same trends and how the model presents a good agreement with the experimental data.

The high accuracy of the model, that fits well with different temperatures ranging from 90 to $180^{\circ} \mathrm{C}$, shows how the ongoing reaction is the same but made faster or slower because of the effect of temperature. In this case, as for the other properties studied, the time/temperature equivalency is effective: different temperatures can result with the same effects in different amount of time.

\section{Moisture relations modification}

As shown in Fig. 4, the moisture content at different equilibrium conditions decreases significantly with the thermal modification intensity. The longer the treatment duration, the lower becomes the $E M C$; and the higher the treatment temperature, the faster the EMC reduction. The $E M C$ reduction is generally ascribed to the degradation of hemicelluloses that leads to a reduction of hydroxyl groups and then to a lower capacity of the cell wall to bond with water. Crosslinking between molecules can also be part of the reason of reduction of water bonding sites. Esteves \& Pereira (2009) have also shown an enhanced inaccessibility of cellulose hydroxyl groups to water molecules due to the increase of cellulose crystallinity. Repellin \& Guyonnet (2005) studied the swelling of heat-treated beech wood by differential scanning calorimetry in relation to chemical composition, and concluded that the reduction of wood swelling could not be attributed only to the disappearance of adsorption sites by hemicellulose destruction, but other phenomena such as structural modifications and chemical changes of lignin might also play an important role. Fig. 4 also shows the behaviour of the shrinkage coefficients $(\beta)$ in $\mathrm{R}, \mathrm{T}$, and $\mathrm{L}$ directions as determined from eqn. 4 . The total shrinkage gradually decreases with the treatment intensity and it decreases faster at higher temperatures, showing a behaviour in line with the expectations and a good predictability by the model. The specific shrinkage coefficients $\left(\beta^{\mathrm{s}}\right)$ as computed from eqn. 5 are also reported in Fig. 4: the $T$ shrinkage coefficient is almost twice as the R shrinkage coefficient, while the $L$ is negligible (this behaviour is in line with the expectations). It is not surprising that the specific shrinkage coefficients does not vary significantly with the treatment temperature and duration while the total shrinkage coefficients $(\beta)$ decreases, the EMC also decreases. This statement is supported by Hill (2006) and Hill et al. (2012) and finds its rationale in the fact that, even if sorption sites are lost during thermal modification, in order to get to the same shrinkage or swelling, the same amount of water must be lost or adsorbed. As a direct consequence, it is important to
Fig. 3 - Physical properties, measured at dry state, evolution over treatment duration for different modification temperatures. The markers are the experimental data while the lines are the identified model. The time axis scale is logarithmic.
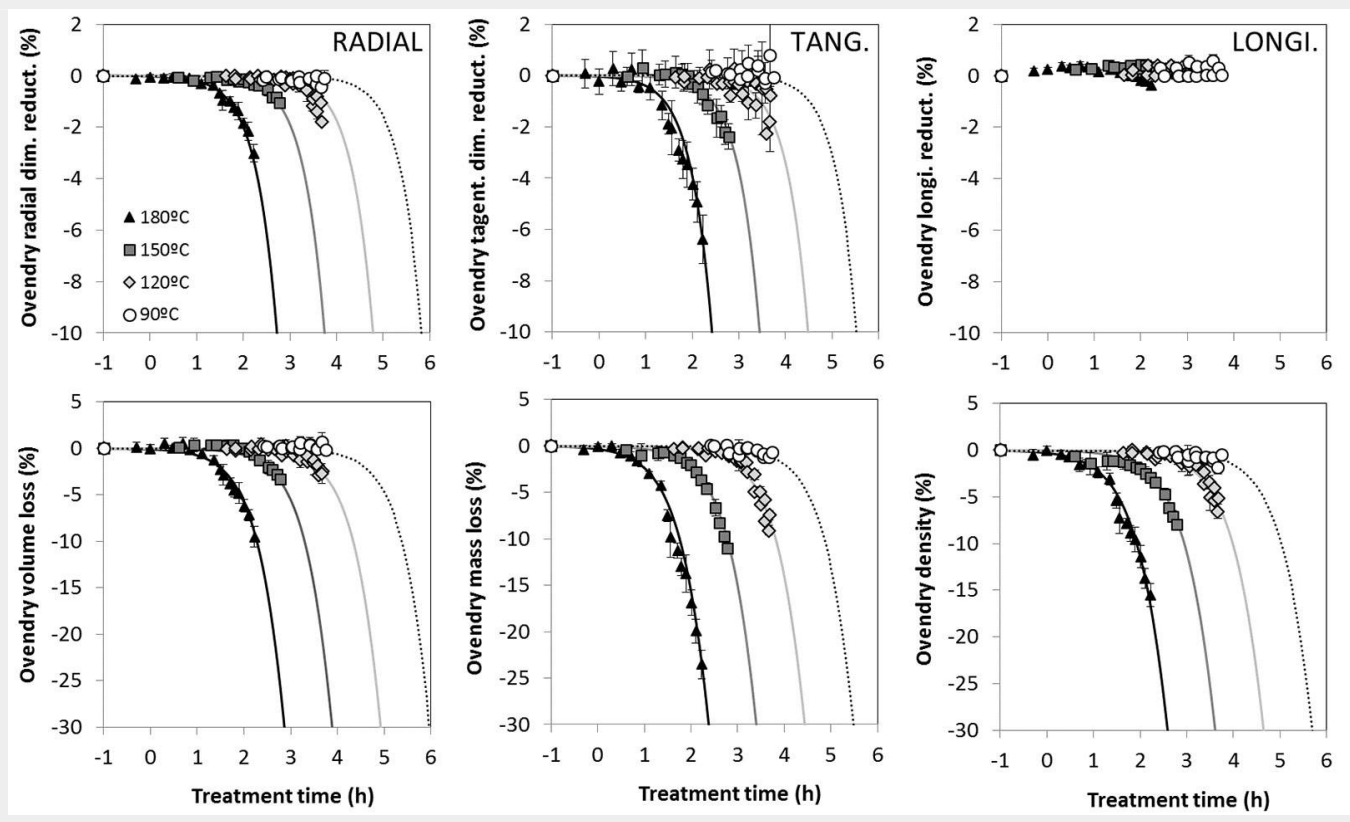

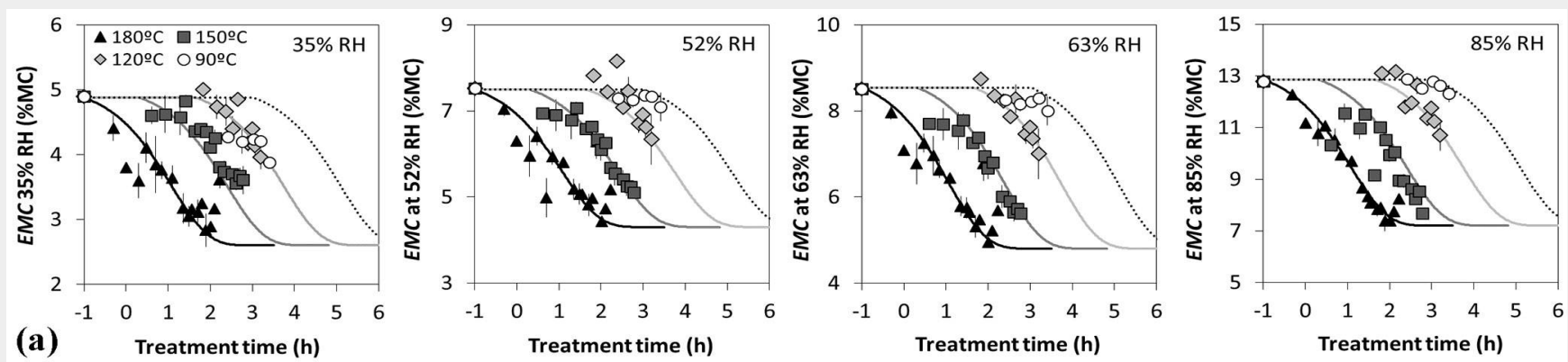

(b)
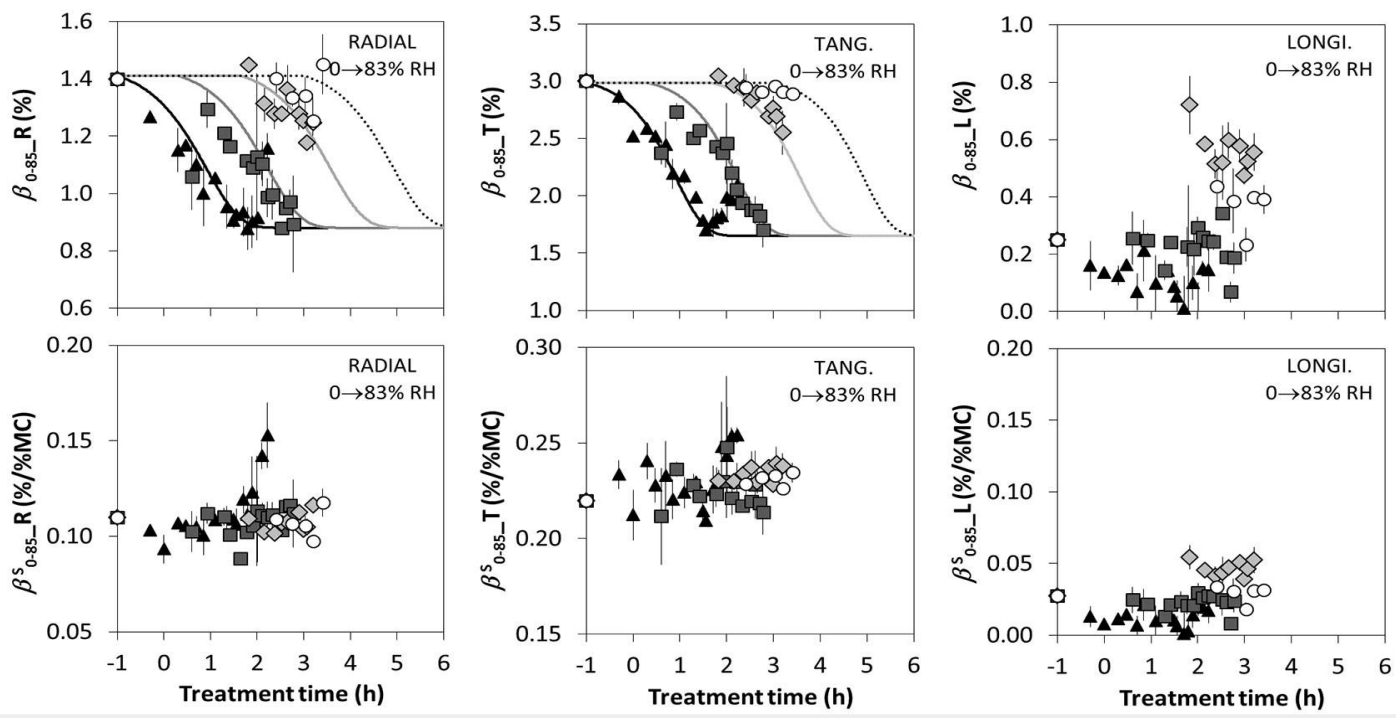

Fig. 4 - Moisture relations vs. treatment temperature and duration (time axis is in logarithmic scale). Symbols represent the experimental data, while the lines are the identified model. (a) Equilibrium Moisture Content (EMC) measured at 35\%, 52\%, 63\% and $85 \%$ of relative humidity and $20^{\circ} \mathrm{C}$. (b) Values of the shrinkage coefficients $(\beta)$ and specific shrinkage coefficients $\left(\beta^{5}\right)$ in the main anatomical directions ( $\mathrm{R}, \mathrm{T}$ and $\mathrm{L}$ ) measured passing from the equilibrium condition with $85 \% \mathrm{RH}$ and $20^{\circ} \mathrm{C}$ to the oven dry state.

consider that the observed increase in di- fitting performed to identify the GAB coefmensional stability (largely exposed in liter- ficients for the different moisture conature) is mainly due to a general reduction tents, the treatment durations, and the difof the equilibrium moisture content.

As regards the hygrothermal behaviour, the control samples (untreated) studied in this paper exhibit a sorption behaviour that leads to the following $G A B$ coefficients: $w_{m}=5.1 \%, K=0.74$, and $C=11.0$. The
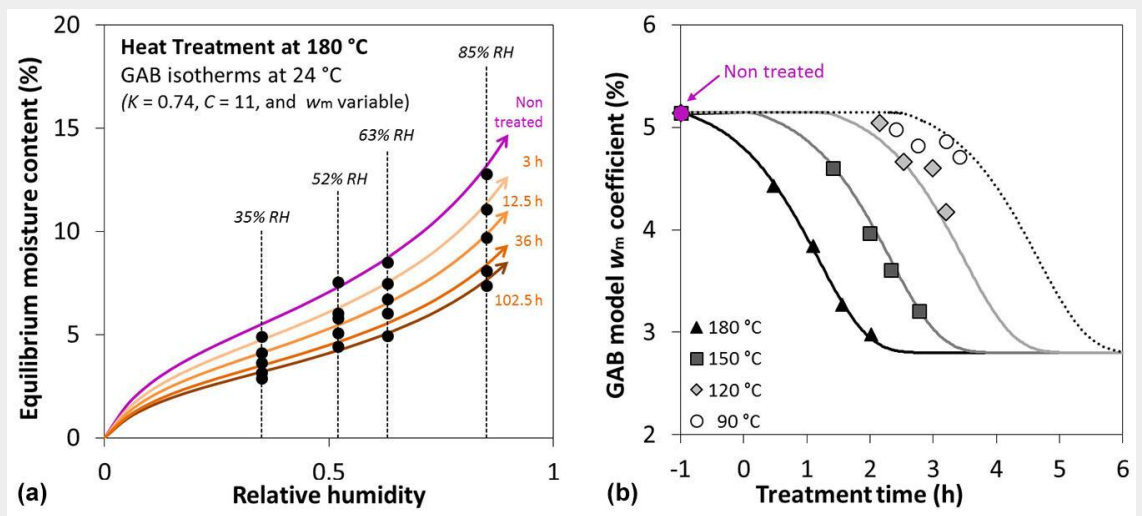

Fig. 5 - (a) Adsorption isotherm of a sample thermally modified at $180{ }^{\circ} \mathrm{C}$ at different durations. Sorption curves (plain lines) arise from a GAB sorption model identified on the experimental data (dots). (b) Evolution of the GAB model coefficient $w_{m}$ over heat treatment time (horizontal axis, in logarithmic scale) and duration; symbols represent the experimental points and the lines are the identified model. wood treated at $180{ }^{\circ} \mathrm{C}$ for different durations is reported for an isotherm at $24^{\circ} \mathrm{C}$. It clearly shows how modified wood presents a lower EMC than the control and how the treatment duration affects the EMC decrease. The effect is the same for all the tested modification temperatures. This is a very important factor for modified wood because a generally lower $E M C$ results in a better resistance to biological degradation. It can also be noted how the EMC reduction is higher for high $R H$ than for low $R H$. In Fig. 5 b, the evolution of $w_{m}$ with different treatment temperatures and durations is shown. The trends clearly shows how the kinetic analysis can be successfully applied also to $G A B$ coefficients.

\section{Mechanical properties modifications}

The changes in mechanical properties due to thermal modification, measured at dry state, are reported in Fig. 6 .

As a general rule the mechanical performances are markedly reduced by the thermal modification. The higher the treatment duration, the higher the reduction. The temperature, as for the other processes, accelerates the reaction. This reduction directly depends on the cell wall loss, that has a negative effect on the stiffness (MOE) both in $\mathrm{L}$ and $\mathrm{R}$ directions. This behaviour is widely described in the literature 
(e.g., Beall \& Eickner 1970, Nilsson \& Rowell 2012). Several research works report the fact that thermal modifications improve the stiffness of the material in the initial phase (Esteves \& Pereira 2009) before dropping drastically afterward. It is worth pointing out that the experimental data shown in Fig. 6 are not exhibiting such behaviour. The above authors believe that this behaviour is a direct consequence of the dry state condition prepared for testing the specimen. The thermal modification results in loss of cell wall material but also in a decreased EMC that could result in an apparent stiffness increase. Thus, the conclusions on the increase of the initial stiffness generally observed by the aforementioned authors has to be mitigated, since the moisture content is reduced as well during the heat treatment. In order to understand the role of cell wall loss and $E M C$ variation on the stiffness at low modification rates, the stiffness measured at dry state was corrected according to the empirical model proposed by Guitard (1987) and reported in eqn. 12 (see below). The stiffness at $20{ }^{\circ} \mathrm{C}$ of temperature and $65 \%$ of relative humidity $\mathrm{MOE}_{\mathrm{L}}{ }^{\mathrm{EMC}}$ was then computed according to the EMC levels measured in this work as follows (eqn. 12):

$$
\begin{aligned}
& M O E_{L}^{E M C}=M O E_{L}^{E M C_{r f f}}\left[11-0.015 \cdot\left(E M C-E M C_{r e f}\right)\right] \\
& M O E_{R}^{E M C}=M O E_{R}^{E M C_{r f}} \cdot\left[1-0.030 \cdot\left(E M C-E M C_{r e f}\right)\right]
\end{aligned}
$$

As shown in the Fig. S1 (Supplementary material), the oven dry stiffness does not increase at low modification rates but remains constant before decreasing. On the other hand, the apparent stiffness computed at standard environmental conditions $\left(20^{\circ} \mathrm{C}\right.$ of temperature and $65 \%$ of relative humidity) increases at low modification rates as a consequence of the moisture content reduction due to the thermal modification. According to Esteves \& Pereira (2009), some authors explain the increased stiffness by the increase of cellulose crystallinity. Because this behaviour was not observed in our experimental work at dry state, only the variation of the equilibrium moisture content seems to justify the initial improvement in stiffness. Similar conclusions could be drawn on the strength trend and other mechanical properties when an apparent improvement for low modification rates is reported (Finnish ThermoWood Association 2003).

To summarize, during the thermal modification: (a) for low modification rates (under $5 \%$ of mass loss), the stiffness reduction because of the cell wall degradation cannot compensate the stiffness increase due to lessening of moisture content, resulting in an apparent improvement of the stiffness; (b) for higher modification rates (greater than $5 \%$ of mass loss), the trend is reversed because the cell wall degradation has a stronger impact than the moisture content reduction on the apparent stiffness. As regards the natural aging of wood, some authors (Kohara 1952, Obataya 2007)
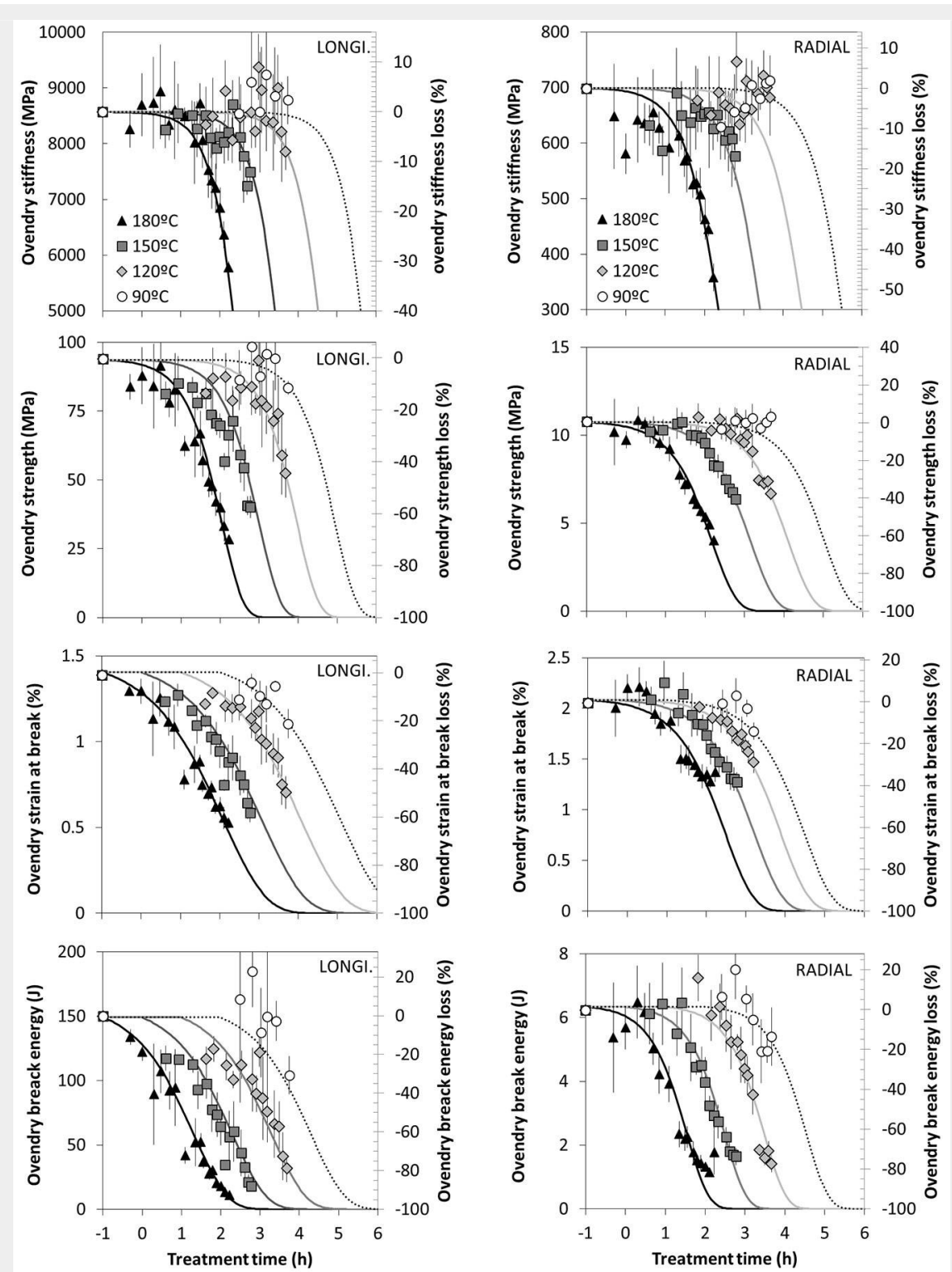

Fig. 6 - Longitudinal (left column) and radial (right column) mechanical properties evolution over modification time (horizontal axis, in logarithmic scale); symbols represent the experimental points and the lines are the identified model.

gave the same conclusions about the improvement of the mechanical properties during the first 300 years of natural aging before a drop of the performances.

The strength $(M O R)$ is lowered severely as well, e.g., by $80 \%$ while the MOE had been reduced by about $30 \%$ at the end of the 168 hours of heat treatment at $180^{\circ} \mathrm{C}$. MOR can drop until being almost null for very extreme treatments (high temperature and/or long exposure time). Several authors studied the strength modification after heat treatment (Winandy \& Lebow 2001, Froidevaux et al. 2012) and observed the same effects. The maximal strain at breaking and the energy needed to break the samples in flexural tests are provided in Fig. S2 (Supplementary material); those properties exhibit the same trends than the MOE and the MOR. The kinetic model proposed and fitted to the experimental data follows very accurately the mechani- cal properties over treatment duration and temperatures.

\section{Properties relations to mass loss}

The property modifications occurring under thermal modification in conventional oven can be also related to mass loss. This is important because mass loss is one of the easiest parameters to be measured during the treatments and one of the best indicators of treatment intensity, as reported by Candelier et al. (2016). Hence, all relevant properties (those significantly affected by heat treatment) are plotted against mass loss variation in Fig. S2 (Supplementary material). The relation between mass loss and a given property variation can be very different depending on the property considered: monotonous and linear relationships are observed in some cases or much more complex relations in others. First, the modifications are all 
strongly related to the mass loss; second, the heat treatment temperature does not produce significant differences, since all experimental points, whatever the temperature, are overlapping. The trends, being independent on the temperature, clearly confirm the time-temperature equivalency principle. For several property variations, such as oven-dry dimensions, oven-dry volume, and oven-dry density, the trends are very close to linearity up to very large mass loss rates; in those specific cases, a linear approximation is provided in the graphs allowing to compute the property variation, from a measured mass loss, in an easier way than fully applying the kinetic models proposed in this work. For the other properties, the behaviour could be simplified with a linear relation but up to $5 \%$ mass loss only. The absence of a linear trend above that level suggest that the properties do not follow the same kinetics and that heat treatments are complex processes to understand and control.

Nevertheless, the kinetic model seems not to be perfectly accurate to predict the variations of few properties such as moisture content, swelling/shrinkage coefficients, and strain at break for mass losses greater than $20 \%$. These unexpected results, concerning a limited number of conditions, are possibly due to experimental issues since an increase of the moisture content appears not plausible.

\section{Conclusions}

The present work has made an assessment of the changes of most properties of poplar wood when subjected to thermal modification applied with different temperatures and durations in a conventional atmosphere. The variation of the physical and mechanical properties as well as the wood-moisture relations were modelled with a modified Arrhenius law approach and a pre-exponential dependency to temperature was identified; the model parameters identifications for each properties are summarized in the Tab. S1 (Supplementary material). The proposed models showed a very good ability to describe the experimental data for temperatures ranging from 90 to $180{ }^{\circ} \mathrm{C}$. This approach has shown to work well up to $260^{\circ} \mathrm{C}$ (Goli et al. 2014). The kinetic model proposed is evidently accurate for colour, mass loss and hydric shrinkage. However, a noticeable deviation was observed in hygroscopic and mechanical parameters for heating at low temperatures $\left(90^{\circ} \mathrm{C}\right)$. This could be due to different chemical reactions occurring at higher temperatures compared to those at lower temperatures; this statement should be mitigated by the few data obtained to check the model reliability at that low temperature, because of the very long treatment duration (10 months of treatment has allowed only to obtain 4 experimental points).

This kind of model could be profitably used in industry to predict any property variation resulting from a treatment ranging between the experimental maximal and minimal temperature. The good agreement of the data from $90{ }^{\circ} \mathrm{C}$ to $180^{\circ} \mathrm{C}$ with the model predictions shows how the chemical degradation processes occurring at the different temperatures are not very far the one from the other. However, the present study highlights the fact that properties are modified at different time and with different kinetics during the heat treatment. Moreover, the good fit of very low treatment temperatures with the other data suggests that possibly the thermal modification of wood cannot be considered very far from conventional aging of wood.

The model proposed could help modelling the whole set of properties variation in a given material for any industrial treatment, even though it has some limitations in terms of risk of fire under such conditions. Our results demonstrates that it is possible to target a specific final product quality and to choose the suitable treatment to apply. The direct transposition of the results of this work to actual industrial wood modification processes is currently ongoing under steam environment.

\section{Acknowledgments}

The authors acknowledge funding from JSPS (Japan Society for the Promotion of Science) and Professor Shuichi Kawai from the RISH, Kyoto University (Japan) for hosting in his research team. Special thanks to Prof. Luca Uzielli (Dept. GESAAF, Florence University, Italy) who provided the wood material for this study and for the discussion and advises over many years on wood science and cultural heritage wooden artefacts preservation.

\section{References}

Agrawal RK (1985). On the use of the Arrhenius equation to describe cellulose and wood pyrolysis. Thermochimica Acta 91: 343-349. - doi: 10.1016/0040-6031(85)85227-8

Barbero EJ, Ford KJ (2004). Equivalent time temperature model for physical aging and temperature effects on polymer creep and relaxation. Journal of Engineering Materials and Technology 126: 413. - doi: 10.1115/1.1789956

Beall FC, Eickner HW (1970). Thermal degradation of wood components: a review of the literature. United States Forest Products Laboratory, Madison, WI, USA, pp. 26. [online] URL: http://www.cabdirect.org/cabdirect/abstract/19 700601495

Bekhta P, Niemz P (2003). Effect of high temperature on the change in color, dimensional stability and mechanical properties of Spruce wood. Holzforschung 57: 539-546. - doi: 10.1515/ HF.2003.080

Bratasz L, Kozowska A, Kozowski R (2011). Analysis of water adsorption by wood using the Guggenheim-Anderson-de Boer equation. European Journal of Wood and Wood Products 70: 445-451. - doi: 10.1007/s00107-011-0571-x

Brown DJ (1982). The questionable use of the Arrhenius equation to describe cellulose and wood pyrolysis. Thermochimica Acta 54: 377379. - doi: 10.1016/0040-6031(82)80032-4

Calvini P, Gorassini A, Merlani AL (2008). On the kinetics of cellulose degradation: looking beyond the pseudo zero order rate equation. Cellulose 15: 193-203. - doi: 10.1007/s10570-007-916 2-8

Candelier K, Hannouz S, Elaieb M, Collet R, Dumarçay S, Pétrissans $A$, Gérardin P, Pétrissans $M$ (2015). Utilization of temperature kinetics as a method to predict treatment intensity and corresponding treated wood quality: durability and mechanical properties of thermally modified wood. Maderas Ciencia y Tecnologia 17: 253-262. - doi: 10.4067/S0718-221X20150050000 24

Candelier K, Thevenon M-F, Petrissans A, Dumarçay S, Gérardin P, Pétrissans M (2016). Control of wood thermal treatment and its effects on decay resistance: a review. Annals of Forest Science 73: 571-583. - doi: 10.1007/s13595-016-05 41-x

Chaouch M, Dumarçay S, Pétrissans A, Pétrissans M, Gérardin P (2013). Effect of heat treatment intensity on some conferred properties of different European softwood and hardwood species. Wood Science and Technology 47: 663673. - doi: 10.1007/s00226-013-0533-z

Dlouhá J, Gril J, Clair B, Alméras T (2008). Evidence and modelling of physical aging in green wood. Rheologica Acta 48: 333-342. - doi: 10.1007/s00397-008-0325-9

Dlouhá J, Clair B, Arnould O, Horáček P, Gril J (2009). On the time-temperature equivalency in green wood: characterisation of viscoelastic properties in longitudinal direction. Holzforschung 63: 327-333. - doi: 10.1515/HF.2009.059 Dureisseix D, Marcon B (2011). A partitioning strategy for the coupled hygromechanical analysis with application to wood structures of cultural heritage. International Journal for Numerical Methods Engineering 88: 228-256. - doi: 10.1002/nme.3173

Emsley AM, Stevens GC (1994). Kinetics and mechanisms of the low-temperature degradation of cellulose. Cellulose 1: 26-56. - doi: 10.100 7/BFo0818797

Enayati AA, Taheri F (2012). Study of dimensional stability and EMC of poplar wood (Populus alba) treated at different heat-temperature and initial moisture content. In. Proceedings of the Cost Action FPo904 Meeting "Thermo-HydroMechanical Wood Behaviour and Processing”. Nancy (France) 26-28 Mar 2012. Université de Lorraine, Nancy, France, pp. 50-51. [online] URL: http://www.cost-fpogo4.ahb.bfh.ch/NR/rd onlyres/ADEFFC2A-8392-4885-8D43-1E418BD7B 260/0/BookOfAbstracts.pdf

Endo K, Obataya E, Zeniya N (2016). Effects of heating humidity on the physical properties of hydrothermally treated spruce wood. Wood Science and Technology 50: 1161-1179. - doi: 10.1007/s00226-016-0822-4

Esteves BM, Pereira HM (2009). Wood modification by heat treatment: a review. BioResources 4: 370-404

Fengel D, Wegener G (1989). Wood - chemistry, ultrastructure, reactions. Journal of Polymer Science Part C: Polymer Letters 23 (11): 601-602. - doi: 10.1002/pol.1985.130231112

Finnish ThermoWood Association (2003). Ther- 
moWood handbook. Finnish ThermoWood Association, Helsinki, Finland, pp. 66.

Froidevaux J, Volkmer T, Ganne-Chédeville C, Gril J, Navi P (2012). Viscoelastic behaviour of aged and non-aged spruce wood in the radial direction. Wood Material Science and Engineering 7: 1-12. - doi: 10.1080/17480272.2011.629735

Ganne-Chédeville C, Jääskeläinen A-S, Froidevaux J, Hughes M, Navi P (2012). Natural and artificial ageing of spruce wood as observed by FTIR-ATR and UVRR spectroscopy. Holzforschung 66: 163-170. - doi: 10.1515/HF.2011.148 Gillen KT, Clough RL (1989). Time-temperaturedose rate superposition: a methodology for extrapolating accelerated radiation aging data to low dose rate conditions. Polymer Degradation and Stability 24: 137-168. - doi: 10.1016/0141-3910 (89)90108-0

Goli G, Marcon B, Fioravanti M (2014). Poplar wood heat treatment: effect of air ventilation rate and initial moisture content on reaction kinetics, physical and mechanical properties. Wood Science and Technology 48: 1303-1316. doi: 10.1007/s00226-014-0677-5

Guitard D (1987). Mécanique du matériau bois et composites [Mechanic of wood and composite materials]. Cepadues Editions, France, pp. 238. [In French]

Gérardin P (2016). New alternatives for wood preservation based on thermal and chemical modification of wood a review. Annals of Forest Science 73: 559-570. - doi: 10.1007/s13595015-0531-4

Herrera A, Soria S, Araya C (1986). A kinetic study on the thermal decomposition of six hardwood species. European Journal of Wood and Wood Products 44: 357-360. - doi: 10.1007/ BF02612744

Hill C (2006). Wood modification. In: "Chemical, thermal and other processes". Wiley and Sons Ltd., Chichester, UK, pp. 260. - doi: 10.1002/047 0021748.ch5

Hill C, Ramsay J, Keating B, Laine K, Rautkari L, Hughes M, Constant B (2012). The water vapour sorption properties of thermally modified and densified wood. Journal of Material Science 47: 3191-3197. - doi: 10.1007/s10853-0116154-8

Hutchinson JM (1995). Physical aging of polymers. Progress in Polymer Science 20: 703-760. - doi: 10.1016/0079-6700(94)00001-I

Johansson D (2005). Strenght and colour response of solid wood to heat treatment. PhD Thesis, Luleå University of Technology, Sweden, pp. 85.

Kamdem DP, Pizzi A, Jermannaud A (2002). Durability of heat-treated wood. European Journal of Wood and Wood Products 60: 1-6. - doi: 10.1007/s00107-001-0261-1

Kohara J (1952). Studies on the durability of wood. I: Mechanical properties of old timbers. Bulletin of Kyoto Prefecture University 2: 116131. [In Japanese]
Laidler KJ (1996). A glossary of terms used in chemical kinetics, including reaction dynamics. Pure and Applied Chemistry 68: 149-192. - doi: 10.1351/pac199668010149

Marcon B (2009). Hygromécanique des panneaux en bois et conservation du patrimoine: des pathologies aux outils pour la conservation [Hygromechanics of wood panel paintings and cultural heritage conservation]. PhD Thesis, University of Montpellier 2, France, and Unversity of Florence, Italy, pp. 142. [In French]

Matsuo M, Yokoyama M, Umemura K, Sugiyama J, Kawai S, Gril J, Kubodera S, Mitsutani T, Ozaki H, Sakamoto M, Imamura M (2011). Aging of wood: analysis of color changes during natural aging and heat treatment. Holzforschung 65: 361-368. - doi: 10.1515/HF.2011.040

Matsuo MU, Mitsui K, Kobayashi I, Kohara M, Yoshida M, Yamamoto H (2016). Effect of hygrothermal treatment on wood properties: color changes and kinetic analysis using four softwood and seven hardwood species. Wood Science and Technology 50: 1145-1160. - doi: 10.10 07/s00226-016-0833-1

Navi P, Sandberg D (2012). Thermo-hydro-mechanical processing of wood. EPFL Press, Lausanne, Switzerland, pp. 280. [online] URL: http://books.google.com/books?id=wO3-HP5IC $\mathrm{XoC}$

Nilsson T, Rowell R (2012). Historical wood structure and properties. Journal of Cultural Heritage 13: S5-S9. - doi: 10.1016/j.culher.2012. 03.016

Obataya E (2007). Caracteristiques du bois ancien et technique traditionnelle japonaise de revêtement pour la protection du bois [Characteristics of ancient wood and traditional Japanese technique of coating for wood protection]. In: Actes de la journée d'étude "Conserver aujourd'hui: les 'vieillissements' du bois". Paris, France, pp. 4-25. [in French]

Obataya E, Shibutani S, Hanata K, Doi S (2006). Effects of high temperature kiln drying on the practical performances of Japanese cedar wood (Cryptomeria japonica). II: Changes in mechanical properties due to heating. Journal of Wood Science 52: 111-114. - doi: 10.1007/s100 86-005-0748-1

Pétrissans A, Younsi R, Chaouch $M$, Gérardin P, Pétrissans $M$ (2014). Wood thermodegradation: experimental analysis and modeling of mass loss kinetics. Maderas Ciencia y Tecnologia 16: 133-148. - doi: 10.4067/S0718-221X20140050000 11

Rapp AO (2001). Review on heat treatment of wood. In: Proceedings of COST E22 Special Seminar "European Thematic Network for Wood Modification" (Rapp AO ed). Antibes (France) 9 Feb 2001. European Commission Research Directorate, Belgium and BFH - The Federal Research Centre for Forestry and Forest Products, Hamburg, Germany, pp. 66. [online]: http://projects.bre.co.uk/ecotan/pdf/
Heat_treatment_processes_Andreas_Rapp \%20.pdf

Repellin V, Guyonnet R (2005). Evaluation of heat treated wood swelling by differential scanning calorimetry in relation with chemical composition. Holzforschung 59: 28-34. - doi: 10.1515/HF.2004.131

Sandberg D, Haller P, Navi P (2013). Thermo-hydro and thermo-hydro-mechanical wood processing: an opportunity for future environmentally friendly wood products. Wood Material Science and Engineering 8: 64-88. - doi: 10.108 o/17480272.2012.751935

Shafizadeh F, Peter PC (1977). Thermal deterioration of wood. Wood Technology: Chemical Aspects 43: 57-81. - doi: 10.1021/bk-1977-0043.ch 005

Stamm AJ (1956). Thermal degradation of wood cellulose. Industrial and Engineering Chemistry 48 (3): 413-417. - doi: 10.1021/ie51398a022

Struik LCE (1978). Physical aging in amorphous polymers and other materials. University of Delft, Elsevier, Netherland, pp. 229. - [online] URL: http://citeseerx.ist.psu.edu/viewdoc/dow nload?doi=10.1.1.899.1753\&rep=rep1\&type=pdf Struik LCE (1997). On McCrum's sequential aging theory. Polymer 38: 5243-5246. - doi: 10.1016/So 032-3861(97)00022-0

Ströfer-Hua E (1990). Experimental measurement: interpreting extrapolation and prediction by accelerated aging. Restaurator 11: 254266. - doi: 10.1515/rest.1990.11.4.254

Tjeerdsma BF, Boonstra M, Pizzi A, Tekely P, Militz H (1998). Characterisation of thermally modified wood: molecular reasons for wood performance improvement. European Journal of Wood and Wood Products 56: 149. - doi: 10.1007/s001070050287

Winandy JE, Lebow PK (2001). Modeling strength loss in wood by chemical composition. Part I: An individual component model for southern pine. Wood and Fiber Science 33: 239254.

Young JF (1967). Humidity control in the laboratory using salt solutions. Journal of Applied Chemistry 17: 241-245. - doi: 10.1002/jctb.50101 70901

\section{Supplementary Material}

Tab. S1 - Settings of the modelling performed according to Goli et al. (2014).

Fig. S1 - Effect of the moisture content reduction on the apparent stiffness at normal conditions $\left(65 \% \mathrm{RH}\right.$ and $\left.20^{\circ} \mathrm{C}\right) \mathrm{com}$ pared to the oven dry state stiffness ( $0 \%$ $\mathrm{MC})$.

Fig. S2 - Dependencies of the different studied properties on the mass loss.

Link: Marcon_2422@supploo1.pdf 